\title{
Biotech and pharma face more costly clinical trials
}

Biotechnology and pharmaceutical companies could face longer and more costly clinical trials should recommendations in a new report issued in June by the US Department of Health and Human Services (HHS; Washington, DC) Office of the Inspector General be implemented. The report, "A Time for Reform," finds that institutional review boards (IRBs) - originally established to protect human subjects in clinical trials-are stressed to a point in which protection of clinical trial participants is seriously compromised. Although patient advocacy groups say the report does not go far enough, industry organizations do not want major changes to the IRB system, warning that they might increase clinical costs and delay drug approvals.

According to US federal law, any research protocol receiving federal funding, and every drug and device seeking US Food and Drug Administration (FDA; Rockville, MD) approval, must be scrutinized and approved by an IRB before reaching the clinic. (The two HHS agencies responsible for IRB oversight are the Office for Protection from Research Risks [OPRR] and the FDA.) Specifically, IRBs should review protocol design, examine the ratio of risk to potential benefit for the patient, and ensure that informed consent of trial subjects has been obtained. Until recently, IRBs typically comprised local, voluntary groups of physicians, other health-care personnel, and one member of the community; IRBs were situated in the same locale as medical centers in which the research took place.

The report is the result of a year-long study that examined the effects of several changes in the drug development and testing landscape over the 20 years since IRBs were established. Among the changes that have produced a "pressure-cooker atmosphere within the IRB system," the report blames increased commercialization of research, the proliferation of multicenter trials, new types of research including genetic protocols - the assessment of which requires specialized knowledge-and new types of informed consent, an increased number of research proposals, and the rise of patient consumerism.

As well as criticizing IRBs for reviewing too many protocols too quickly and with too little expertise (for example, it is not unusual for an IRB to review a large number of complex protocols in two hours), the report says IRBs conduct minimal continuing review of research that is approved, and provide little oversight of the informed consent process (resulting in consent obtained often through emphasis on benefits without proper disclosure of risks) or ensure that the interests of subjects are being protected during the course of the research. It warns that advertisements for patient participation stress benefits and "treatment" aspects, with minimal mention of risks associated with the research.

According to the report, minimal "outside" representation (typically one member of the local community) is insufficient to

\section{Report recommendations} could lead to closer scrutiny of research protocols, making it harder to get IRB approval, resulting in delayed institutional \section{approval.}

give IRBs important counterbalance to institutional or commercial interests conferred by, for instance, the funding that drug companies give to institutions for clinical trials. In comments included in the report, Sidney Wolfe of the Public Citizen's Health Research Group (Washington, DC), a patient advocacy organization, says, "It is particularly important to temper the institutional enthusiasm with these more disin terested parties."

The report also recommends appointing more nonscientific and noninstitutional IRB members, and the prohibition of IRB equity owners from participating in the IRB review process. While those in the biotechnology industry have been somewhat reluctant to comment, Wolfe thinks the report does not go far enough. He further suggests that the OPRR "be removed from the NIH because of conflict of interest."

The last fow years have seen the emergence of frecstanding "for hire" IRBs. These are not usually locally based and many, the report suggests, seek to pleasc their sponsors/customers. Drug companies, unhappy with reviews of an indepen. dent (institutionally affiliated) IRB, may seek out more accommodating IRBs. The report recommends that IRBs should be registered federally.

It also recommends that both the FDA on-site inspection process and the NIH/OPRR assurance process should be revamped. The OPRR, it says, focuses almost entircly on upfront assurances, while the
FDA relies on compliance-focused inspections. The report urges notification of both multisite trials and FDA action against investigators, and calls for increased IRB awareness of on-site practices at clinical trials. It also suggests holding IRBs accountable for results by regular performance reviews.

The report also proposes an IRB educational program in which members would be trained in technical and ethical subjects. This sentiment is echoed by the Biotechnology Industry Organization (BIO; Washington, DC), which says it "supports bolstering education of IRB members, if it docs not put an added burden on them."

Another proposal is to devote adequate resources for and lessen the workload of IRB members. Bert Spilker, senior vice president of scientific and regulatory affairs at PhRMA (Pharmaceutical Research Manufacturers of America; Washington, DC), proposes that regional or national IRBs be used for multicenter trials, allowing greater coordination and less work for local IRBs, as well as speeding up protocol review. Spilker says PhRMA favors any change that would speed drug testing, but he emphasizes that "changes should be made without new laws."

Not surprisingly, although agreeing that the system is stressed, BIO president Carl Feldbaum does not believe "the IRB system is truly in jeopardy." Despite the report, he does not think it is necessary to revamp the IRB system at this time. The pharmaceutical company body is similarly happy with the status quo. "PhRMA believes the system is working well for pharmaccutical company-sponsored trials," says Spilker, who says PhRMA does not want to see IRBs taking a more aclive role in monitoring clinical research. He believes that company or contract research organization oversight is sufficient.

Implementation of the report's recommendations - directed at the OPRR and the FDA-could lead to closer scrutiny of research protocols making it harder to get IRB approval, resulting in delayed institutional approval. Increased clinical trial costs could come from having to employ a subject advocate to explain the protocols to subjects to obtain true informed consent. In addition, regulation of advertising could result in slow recruitment of subjects (if promises of treatment and payment are prohibited.)

The US National Bioethics Advisory Committee (Washington, DC) is also reviewing the protection of research subjects, and is expected to issue report sometime in 1999.

Vicki Brower 